\title{
Food Waste in Developed Countries and Cold Chain Logistics
}

\author{
Hongwei $\mathrm{Li}^{1}$ and Peng $\operatorname{Pan}^{2 *}$ \\ ${ }^{1}$ Bison Transport, Mississauga, Ontario, L4W 3W5, Canada \\ ${ }^{2}$ Tianjin University of Technology, School of Management, Tianjin, 300384, China
}

\begin{abstract}
Food waste is a tough and profound question in the world. Although the development of agricultural technology has effectively promoted the increase of vegetable and fruit production, one-third of global vegetable and fruit production are still wasted. This issue is caused not only by food overproduction or overstock, but also by customers' requirements for fresh products. This paper aims to thoroughly explore the reasons for food waste and provide some solutions to solve this problem, especially from the "Agri-fresh produce supply chain management" perspective. Solutions include improving the cold-chain logistics system and intelligent methods. To clearly analyze reasons for food wastey, this paper interprets the issue from three dimensions (customer, food supply chain, and farm) and then explores solutions.
\end{abstract}

\section{Introduction}

Forty percent of food production is wasted annually in North America, involving every segment of the food supply chain, from farms to end-customers. This paper discusses reasons for that food waste and evaluates solutions, especially from the cold-chain logistics aspect. First, after the introduction and the methodology, this paper examines the food waste problem, including definitions and influences. Then this paper explores the root causes of food waste from customer, logistics, and farm perspectives. Based on the causes, we propose solutions from three dimensions (farm, cold-chain logistics, and recycle work) based on the literature review process.

\section{Methodology}

To ensure the accuracy of the statistics, most of the data in this paper are cited from annual reports published by the Canadian government. The rest of the data are cited from peer journals. As a theoretical basis, we searched topicrelated papers from library databases by using keywords. The keywords we used to search papers are food waste, wasted food, household, fresh product, food supply chain, and similar terms. Because of limited time, we cited data which we collected from European researchers (Finland and UK) rather than doing surveys and collecting first-hand data.

\section{Food Waste Problem}

\subsection{The definition of food waste}

"Waste" can be defined as the intentional discarding of usable but unwanted products or raw materials (Crittenden, Kolaczkowski, \& Kolaczkowski, 1995). It mainly involves solid waste and liquid waste (e.g., milk), and it deeply impacts the environment, economy, and society.

According to the Food and Agriculture Organization of the United Nations, "food waste refers to the decrease in the quantity or quality of food caused by the decisions and actions of retailers, food service providers and consumers" (Patra, Leisnham, Tanui \& Pradhan, 2020). The food waste issue exists in the entire food supply chain from the farm to the final consumers, and it covers raw materials (such as vegetables and fruits) and processed materials (such as cooked food) (Parfitt, Barthel, \& Macnaughton, 2010). This issue is closely related to the nature of food products, including short life-cycle (Doganis, Alexandridis, Patrinos, \& Sarimveis, 2006) and perishablity (Broekmeulen \& van Donselaar, 2009). If we combine general waste and food waste, two types of food waste problems show up: "food loss" and "food waste." Food loss is mainly caused by objective factors, such as post-harvest storage, transportation, and retailing. A common characteristic is that food loss occurs in the food supply chain as well asduring the stages before the final purchase. Farmers, transportation service providers, and dealers take responsibility for and consequences of losses in the food supply chain. Considering the narrow definition of food waste, it occurs at the end of the food value chain (Uzea, Gooch \& Sparling, 2013), such as at wholesale distribution, retailing, and household. One cause is food deterioration. People cannot do anything to save spoiled food but must throw it away. Most of time, loss is due to incorrect food-consumption estimation (Kantor, Lipton, Manchester, \& Oliveira, 1997), therefore over-purchasing, and inappropriate display and storage methods.

This paper emphasizes the fresh food waste issue, perishable in particular, such as fruits and vegetables. Also, to provide a more holistic picture of this research question, this paper analyzes both dimensions of food

\footnotetext{
Corresponding author: panpeng@email.tjut.edu.cn
} 
waste and proposes solutions from different stakeholders' perspectives.

\subsection{The consequences of food waste}

The food waste problem involves various factors and is widespread in the world. It originates from and affects all aspects of the food system and supply chain (Priefer et al., 2016). Based on the data published by the Food and Agriculture Organization (FAO), 1.3billion tons of food are wasted per year, bringing $\$ 940$ billion in economic losses ("Food waste costs global economy $\$ 940$ billion," 2019). Figure1 summarizes the percentages of post-harvest losses in both developing and developed countries, as cited in articles published within the last 30 years. It is estimated that each person in the United States produces approximately 422 grams of consumer food waste per day, which is equivalent to the allocation of 30 million acres of arable land and a large amount of fresh water and other agricultural inputs (Conrad et al., 2018). According to the USDA Economic Research Service (ERS), 30\% of food is wasted at the retail and consumer levels. Americans throw away about 133 billion pounds (60 billion kilograms) of food every year, which is worth about $\$ 161$ billion (Patra, Leisnham, Tanui \& Pradhan, 2020). Further, approximately $40 \%$ of food production and $\$ 27$ billion were wasted in Canada in 2009 (Uzea, Gooch \& Sparling, 2014), significantly increasing by $15 \%$ to $\$ 31$ billion in 2014 (Gooch, Martin V, 2015).

Table 1. Post-harvest loss estimates for fresh fruit and vegetables. (Parfitt et al., 2010)

\begin{tabular}{|c|c|c|c|}
\hline country & commodities & post-harvest losses (\%) & reference \\
\hline \multirow[t]{5}{*}{ Egypt } & all fruits & 20 & \multirow[t]{5}{*}{ Blond (1984) } \\
\hline & all vegetables & 30 & \\
\hline & grape & 28 & \\
\hline & potato & 18 & \\
\hline & tomato & 43 & \\
\hline \multirow[t]{6}{*}{ Venezuela } & broccoli & 49 & \multirow[t]{6}{*}{ Guerra et al. (1998) } \\
\hline & cauliflower & 33 & \\
\hline & celery & 48 & \\
\hline & leek & 20 & \\
\hline & lettuce & 35 & \\
\hline & all FFVs & & \\
\hline \multicolumn{2}{|l|}{ India } & 40 & \multirow[t]{8}{*}{ Rolle (2006) } \\
\hline Indonesia & & $20-50$ & \\
\hline Iran & & $>35$ & \\
\hline Korea & & $20-50$ & \\
\hline Philippines & & $27-42$ & \\
\hline Sri Lanka & & $16-41$ & \\
\hline Thailand & & $17-35$ & \\
\hline Vietnam & & $20-25$ & \\
\hline \multicolumn{4}{|c|}{ loss estimates: less developed countries (research prior to 1981) } \\
\hline & carrots & 44 & \multirow{16}{*}{$\begin{array}{l}\text { National Academy of } \\
\text { Sciences report } \\
(1978) \text { and cited in } \\
\text { FAO (1981) }\end{array}$} \\
\hline & potatoes & $5-40$ & \\
\hline & sweet potatoes & $35-95$ & \\
\hline & yams & $10-60$ & \\
\hline & cassava & $10-25$ & \\
\hline & onions & $16-35$ & \\
\hline & plantain & $35-100$ & \\
\hline & cabbage & 37 & \\
\hline & cauliflower & 49 & \\
\hline & lettuce & 62 & \\
\hline & banana & $20-80$ & \\
\hline & papaya & $40-100$ & \\
\hline & avocado & 43 & \\
\hline & peaches, apricots and nectarines & 28 & \\
\hline & citrus & $20-95$ & \\
\hline & apples & 14 & \\
\hline \multicolumn{4}{|c|}{ loss estimates: US and UK } \\
\hline USA & all FFVs & $2-23$, farm-retail stage & Kader (2005) \\
\hline \multirow[t]{2}{*}{ UK } & all FFVs & approx. 10 , farm-retail stage & Garnett (2006) \\
\hline & 'out-graded' FFVs & $25-40$, rejected by supermarkets & Stuart (2009) \\
\hline
\end{tabular}

The economic losses include both direct and hidden costs. It is easy to estimate the direct losses by calculating the prices of discarded food. However, the direct losses are only the tip of the iceberg (Figure1), because the hidden losses involve many costs, the majority of which are added by the supply chain, such as processing, transportation, and environment. In certain circumstances, fresh food can be compared with bottled beverages. That is, the unit cost of goods themselves is remarkably low due to mass production, but costs are added by the distribution stages, like transportation (e.g., fuel, labor, facilities, tax) and marketing (e.g., fuel, labor, facility, tax). Therefore, the economic losses are far more than the food value itself. They cover the whole food value chain, because every stakeholder in this value chain has added additional value into the fresh product.

In 2018, the World Bank released the World Bank Logistics Performance Index (LPI) ranking. Germany and Japan are the top countries in terms of their comprehensive capabilities and lead the world in the 
development of cold-chain logistics for agricultural products, especially in the construction of cold-chain logistics systems for agricultural products according to the characteristics and needs of their own agriculture. Overall, Europe has the most developed cold-chain logistics industry, spending \$5.8 billion in 2018 and spending \$4.4 billion in Asia and $\$ 3.7$ billion in North America. From the perspective of cold-chain, North America is the largest market, while the Asia-Pacific region, with the highest growth rate, will be in the spotlight in the future. The reason for the rapid growth of the cold-chain market in this area is the increase in population, improving living standards, and the demand for fresh food.

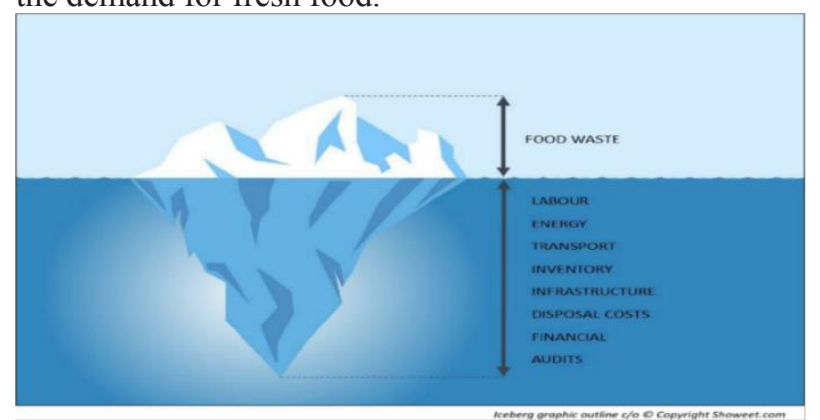

Figure 1. Applying the iceberg theory into food waste issue (Gooch, Martin V, 2015)

In addition, food waste plays a facilitating role in environmental contamination, such as biochemical pollution (Lin et al., 2011). According to the report published by the Cut Waste Grow Profit Forum in 2006, food waste will cause two main environmental issues: "wasted resources and the environmental impact of refuse" (George Morris Centre Value Chain, Management Centre, 2012). We can place the negative effects on the environment into two categories: direct and indirect impacts. Common ways to deal with wasted food are landfills, composters, and incinerators (Gooch, Martin V, 2015), but the landfill is the most common method. Wasted food is buried in soil, left to decay over time. This process produces the harmful greenhouse gasses (Lundqvist, de Fraiture, \& Molden, 2008) of carbon dioxide $(\mathrm{CO} 2)$ and methane. Many regional and global studies have quantified resource waste and environmental consequences due to food loss and food waste across the country (Kashyap and Agarwal et al., 2019). For example, Porter et al. (2016) estimated that global percapita greenhouse gas emissions due to food loss and waste are $323 \mathrm{~kg}$ of carbon dioxide. According to the FAO, about a third of the world's food, or $1.3 \mathrm{bn}$ tonnes, is wasted each year. This is equivalent to 4.4 billion tons of $\mathrm{CO} 2$ emissions (Fan, Zhang, Bhandari \& Yang, 2020). Similarly, in the UK, $75 \%$ of wasted food was landfilled (Iacovidou, Ohandja, \& Voulvoulis, 2012), and these foods were estimated to have produced $20 \mathrm{Mt}$ of $\mathrm{CO} 2$ (Parfitt et al., 2010).

The above data show only one negative effect on the environment - carbon dioxide. Its consequences are momentous. If we cite the iceberg analogy, we can see that there are many unseen negative effects on the environment caused by food waste. Apart from those effects which happen after people throw food away, we must consider the process of replenishing that food. Essentially, we need to become increasingly aware of the potential environmental damage that can be caused by using pesticides and fertilizers (Pinstrup-Andersen, 2002) or water use in the planting crops. The resulting soil and underground water contamination should receive greater attention from people because it is a direct result of food waste.

\section{Exploring the Root Causes of Food Waste}

\subsection{The comparison of food waste in the different stages of the food-value chain}

Table 2 shows a comparison of the food waste situation in different segments in the food value chain between the years of 2010 and 2014. There is no doubt that $90 \%$ of food waste happens in the post-harvest period. Evidence suggests that we should be more concerned with the middle and end segments of the food chain, as well. It is surprising that households accounted for approximately $50 \%$ of the food waste, even if it had decreased $4 \%$ in last four years. Noteworthy is that processing and retailing have produced $30 \%$ of food waste. Further, if we take transportation and distribution into account, we see that about $35 \%$ of wasted food is produced in the food supply chain. The FAOs FLI Index, published in 2019, shows that $13.6 \%$ of the world's food produced in 2016 was wasted from farm to consumer (excluding the retail stage) (Patra, Leisnham, Tanui \& Pradhan, 2020).

Table 2. 2010 vs. 2014 Figures by Value Chain Segment (Gooch, M et al., 2015).

$\begin{array}{llll}\text { Value Chain Segment } & 2010 & 2014 & \text { Change } \\ & \text { Calculations } & \text { Calculations } & \\ \text { On farm } & 9 \% & 10 \% & +1 \% \\ \text { Processing } & 18 \% & 20 \% & +2 \% \\ \text { Transport and distribution } & 4 \% & 4 \% & - \\ \text { Restaurants and Hotels } & 8 \% & 9 \% & +1 \% \\ \text { Retail } & 11 \% & 10 \% & -1 \% \\ \text { Consumers } & 51 \% & 47 \% & -4 \% \\ \text { International catering waste } & - & <1 \% & +<1 \%\end{array}$




\subsection{Consumer}

According to data published by the Value Chain Management Centre, approximately $50 \%$ of food waste comes from households, making it the primary reason for the food waste problem. Many researchers have studied the causes from different perspectives (Corrado, 2007). They have discovered that, in addition to the fresh fruits and vegetables (fresh and perishables), three other types of food contribute to household food waste: drink, bakery, and meals (Quested \& Johnson, 2009). No matter what, the direct cause of the food waste from the households is that people prepare and serve more food than they can consume (Quested \& Johnson, 2009). As a consequence, they have to throw away expired food which they have not eaten in time. Generally, we can separate household food waste into two issues. One is that the waste is caused by excessive purchasing; the other is that the wrong packing methods have been used.

According to Finnish food-chain research, excessive purchasing is directly correlated with the number of family members and prices (Katajajuuri, Silvennoinen, Hartikainen, Heikkilä, \& Reinikainen, 2014).

Figure 2. Influence of household size on the amount of avoidable food waste per household or per person (Koivupuro et al., 2012).

\begin{tabular}{|c|c|c|c|c|c|}
\hline \multicolumn{6}{|l|}{ Descriptive statistics } \\
\hline & \multirow{2}{*}{$\frac{n}{\text { Statistic }}$} & \multirow{2}{*}{$\frac{\text { Range }}{\text { Statistic }}$} & \multicolumn{2}{|l|}{ Mean } & \multirow{2}{*}{$\frac{\text { Std. deviation }}{\text { Statistic }}$} \\
\hline & & & Statistic & Std. error & \\
\hline Single woman & 41 & 86.19 & 29.64 & 3.58 & 22.9 \\
\hline Single man & 17 & 70.20 & 20.65 & 4.68 & 19.30 \\
\hline Household children & 185 & 151.71 & 22.31 & 1.46 & 19.86 \\
\hline Household adults & 136 & 160.78 & 21.50 & 1.80 & 21.04 \\
\hline Valid $n$ (listwise) & 0 & & & & \\
\hline
\end{tabular}

Table 3. Food waste in different household groups (Koivupuro et al., 2012).

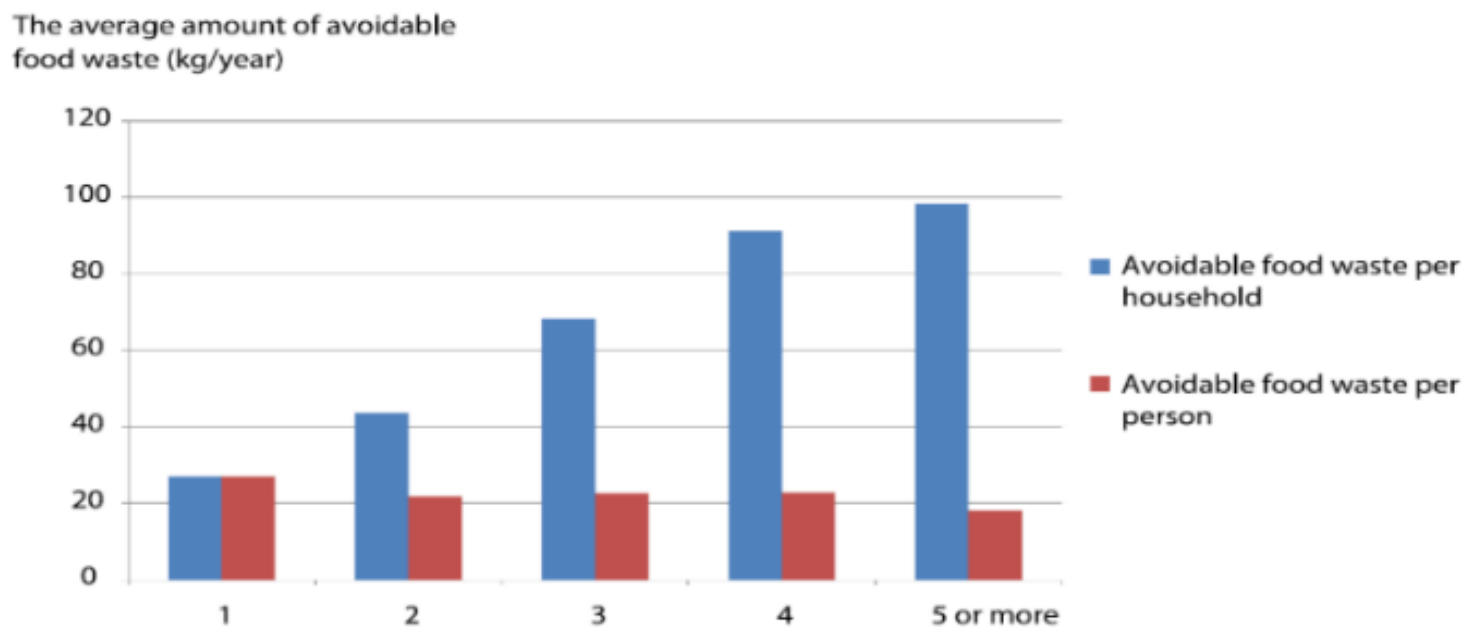

The statistical results (Figure2 and Table 3) published by Koivupuro demonstrate a significant relationship between the family size and food waste. Although the household with more family members simply wasted more, the data of avoidable food waste per capita remained stable. Moreover, the gender factor plays a critical role. Table 3 illustrates that females waste more food, especially when they live alone. Even compared with a household, when measured by the mean of the data, they waste remarkably more.

Normally, we believe that discounted prices will make people buy more and waste more, because people are willing to purchase more, thereby, wasting more. Nevertheless, researchers did not find a causality between discount prices and food-waste level (Katajajuuri et al.,
2014). On the contrary, the people who did not give priority to the prices wasted less (Koivupuro et al., 2012).

Apart from the price element, another influential factor is packaging methods. This paper explains the relationship between food waste and food-packing metrhods. The packaging of food plays a vital role in maintaining food quality and safety and the effects on the environment (Helen Williams, Wikström, \& Löfgren, 2008), because an optimized packaging solution can effectively reduce the food waste rate in both direct and indirect ways (Helén Williams \& Wikström, 2011). Three factors affect the waste rate in packaged foods: easy to empty, to reseal, and to recycle (Helén Williams, Wikström, Otterbring, Löfgren, \& Gustafsson, 2012). "Easy to empty" is decided by the packaging size, material, 
and shape. It involves two dimensions. One is whether or not people can eat all the food before the expired date. The other is if the packaging material or its shape makes it difficult to empty the food which adheres to the packaging surface, such as yoghurt. The feature of "easy to reseal" is especially important for any food that can not be totally eaten at one time, because good reseal solutions can help prolong the safe storage time. These two features of packaging are responsible for keeping the safety and quality of food. On the other hand, the "easy to recycle" focuses on the impact on the environment. Implementing such strategies as utilizing biodegradable packaging materials will reduce the negative effect on the environment, circumventing today's garbage disposal ways in North America, like landfill.

\subsection{Logistics: processing, transportation, and distribution}

Since 1982, the logistics industry has been defined as an integrated management science that covers purchasing, transportation, and storage functions (Lummus, Krumwiede, \& Vokurka, 2001). This industry has been included in strategies to deal with the growing demand for economic development because business activities require support from it. The business world has given this industry opportunities to expand into packaging, storage, processing, information treatment, and other aspects of commodity handling. We combined processing, transportation, and distribution in our analysis, since they are basic elements in the supply chain. With this in mind, along with the nature of food, this paper's discussion is from the perspective of the food-supply chain.

For perishable fresh food, the cold-chain based logistics system drives the operations of the food supply chain. The two large challenges for transiting fresh foods from the field to the end-customer are the limited timeframe and the highstandard storage environment. According to Murthy, "waste in transportation is one of the highest in the food supply chain" (Murthy, Gajanana, Sudha, \& Dakshinamoorthy, 2009). Of course, the concept of transportation is broad. The number of transit segments and lack of unified processing standards are the reasons for food waste in the logistics stage. In the fresh product's processing stage, waste is caused by normal wastage in the processing, such as eliminating bones and roots. Still, other waste during processing is not normal, such as that resulting from uncontrolled temperature. The food supply chain is an integration, after all. No matter which part in the chain does not meet requirements, the food will lose its edible value.

A large proportion of the food waste mentioned above is caused by the cold-chain logistics system not meeting the market demand. To meet this demand, it is necessary to construct and optimize an outstanding cold-chain system from the production stage (the first kilometer) to the consumer purchase stage (the last kilometer). According to the temperature band of the distribution products, it can be divided into frozen products, cold collectables, fresh products, and normal temperature products. It is difficult to make a unified distribution due to the large temperature range, so the distribution systems of frozen products, cold collectables, and other items need to be constructed separately. In order to deliver high-quality food to consumers, thorough real-time temperature monitoring and management is required at each stage of production, processing, circulation and consumption.

\subsection{Farm}

Two wastage types exist in the fields. One is that extreme weather events reduce production; the other is inappropriate harvesting and post-harvesting storage methods in the field. The latter is avoidable.

Although farmers have been keen to increase crop yield and agriculture product quality, about $10 \%$ of food production is wasted in this stage. For fresh products, like fruits, vegetables, and meat, preservation is as significant as improving yield. The relationship of the two is like raising a child -- being pregnant requires much care and effort, but educating a child entails substantial attention. Furthermore, preservation measures should be tqaken from the time before harvest, because the quality of food directly relates to the harvesting process. If farmers ignore the preservation tasks from the first step of production transportation, fresh food will lose the ability to keep fresh, even if these foods have support from advanced coldchain logistics.

Another reason for food waste in the production terminal is overproduction. In other words, fresh products' supply exceeds demands from the market due to wrong predictions.

\section{Proposals for solving the food waste problem in developed countries}

\subsection{Farm}

Farmland is the beginning of the food supply chain. Kummu et al. explains the "postharvest losses" (Kummu et al., 2012), pointing out that at least $40 \%$ of fresh food waste in America is caused by poor storage after harvest (Gunders, 2012). It is also caused by the lack of a reliable transportation network, energy, and the unreliable market system (Rolle, 2006). Applying "gaseous treatments" to block ripening processes is recommended, such as controlling $\mathrm{CO} 2$ or $\mathrm{O} 2$ after the fruit, vegetable, or meat has been harvested (Jedermann, Nicometo, Uysal, \& Lang, 2014). In simpler terms, environmental temperature control and chemical methods are two basic solutions which reduce the decay rate of vegetables and thus reduce post-harvest losses.

Obviously, improving investment on refrigerators and freezers near the farmland is a valid solution to reduce the waste rate. Yet, the fact that the agricultural products production is based on the family unit implies that farmers may lack access to sufficient capital to help them purchase these advanced facilities. A farmer's cooperative organization can help resolve this issue. This is a group that can simulate each family-united farm and contribute to modern storage facilities' development in the rural area. It offers opportunities for farmers to focus on working the 
land and leave trading-related issues to others. The farmer's cooperative would be responsible for keeping products' fresh and carrying out price negotiations with e-commerce companies, thereby reducing risks for individual farmers and increasing income for each production unit.

\subsection{Logistics service provider}

Updating both hardware and software at the same time will have a significant positive effect on improving the performance of cold-chain logistics and reducing the cost of transportation. It is easy to understand the importance of updated hardware facilities, like refrigerated trucks and equipped processing and distribution centers to reduce the food waste rate, meanwhile ensuring the safety and quality of fresh products, but these companies should also pay close attention to scheduling and modeling methods to optimize transportation routes and aim to reduce the cost of transportation and prevent fresh product deterioration.

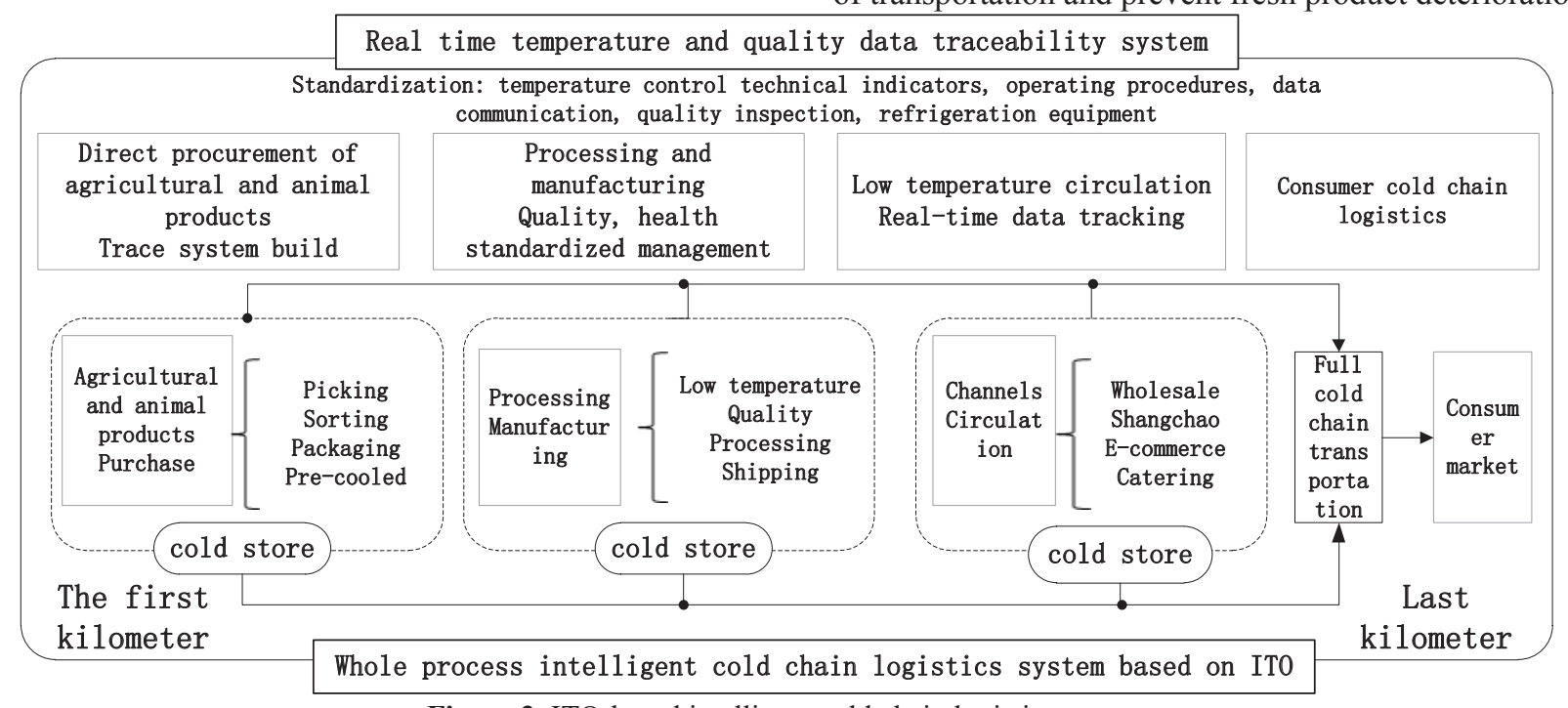

Figure 3. ITO-based intelligent cold chain logistics system

From the enterprise strategy standpoint, freight transportation companies can increase cooperation on cost and profit-sharing (Krajewska, Kopfer, Laporte, Ropke, \& Zaccour, 2008). It may not be necessary for large logistics service providers, because they have enough resources to support their new units and explore business in new markets. Conversely, encouraging small and medium-sized business cooperation and sharing transportation resources will promote the development of the cold-chain logistics. Apart from the horizontal cooperation, vertical separation (involving suppliers, manufacturers, processing and distribution centers, customers, and logistics service providers themselves) affects operation costs and productivity, service, and market position (Cruijssen, Cools, \& Dullaert, 2007).

As shown in Figure 3, it becomes indispensable to build a whole-process preservation system for agricultural products, from pre-cooling, processing factories, marketing channels, to consumers. Fresh food needs to be delivered at low temperature after harvesting. Logistics of the whole temperature management should be carried out by transportation, storage, and classified processing. In order to keep deterioration to a minimum, the cooling method with less degradation must be adopted, and a consistent SCM system for transportation, storage, and cargo distribution with less temperature changes must be developed.

The insufficient control of temperature and humidity relates to the problems in the process of transportation and storage. After all, the problem of "the first kilometer" is mainly a lack of pre-cooling awareness of enterprises. With the help of the sensing system in the Internet of Things technology, temperature and humidity sensors can be installed in the storage shelves of products and inside the boxes of transportation vehicles, so as to collect sensor data and upload it to the cloud platform in real time. When the environmental temperature or humidity is abnormal, real-time instructions will be issued for human or machine control.

Similarly, RFID technology can be used for the optimization of cold-chain logistics. Even so, RFID technology has not been popularized for the following reasons. The first is cost. The RFID electronic tag price is relatively high. Then, there is a lack of major suppliers in the RFID market. Instead, the industry is relatively dispersed. As a result, users have multiple options in choosing RFID solutions, so it is difficult to choose. Finally, technological upgrading requires the replacement of infrastructure and a high dependence on the environmental conditions of facility layout.

With its powerful group-reading function, RFID technology is an effective method for optimizing inventory management of cold-chain logistics. The circulation of cold-chain logistics increases year by year, and it is urgent to improve the efficiency of logistics operations. However, cold-chain logistics pay more attention to temperature control, the increase of material flow, and how to improve the operation efficiency and reduce the rate of product loss. The group reading function of RFID technology coincides with it.

AIOT, a concept emerging in 2018, refers to a system that collects all kinds of information in real time (generally under monitoring, interaction, and connection situations) through a variety of information sensors and makes intelligent analysis of data through machine learning in terminal devices, edge areas, or cloud centers, including positioning, comparison, prediction, and 
scheduling.

The Internet of Things can automate this by providing more relevant streams of data about performance, trends, and experiences. This is cyclical, as logistics can be significantly improved with the help of AI, which provides data through the Internet of Things.

With enough information and the right tools, $\mathrm{AI}$ is the best choice. The data can be compiled into predictive visualizations. It allows the team to react before, rather than during or after, an event. More importantly, predictive models can help identify the outcomes of various decisions or events, resulting in long-term stable operations. If you know you cannot solve a problem because of predictive modeling, you can choose an alternate, more successful approach. Therefore, AIOT is very suitable for optimization of cold-chain logistics. In the cold-chain, predictive modeling can be used to assess and plan market demand and a variety of other situations. For example, a shortage of a particular food or supply can be planned for weeks rather than months in advance.

\subsection{Recycle the wasted food}

For reducing the food waste and increasing the food recycling rate, the Promotion of Utilization of Recyclable Food Waste Act was approved by lawmakers in Japan in 2010 (Takata et al., 2012). Several recycling methods are utilized in food recycle actions: composting (the primary method) (JORA, Japan Organics Recycling Association, 2003), animal feed, bio-gas, and heat recovery (Tanimura, 2008).

\section{Conclusion and Limitations}

This paper has assessed the food waste issue. We analyzed the causes from three perspectives -- customers, logistics, and farms. Our reported statistical data indicates that the waste in households is much more serious than in other places, mainly because of customers' purchasing behaviors (i.e., people are willing to purchase more than they need) and packing methods. Logistics involves many segments and is difficult to control by using the unified standards. Furthermore, we analyzed the waste in the processing segment when explaining the issues in the food supply chain. People often ignore the farm as the start of the food supply chain, while, in fact, $10 \%$ of food waste happens at the farm. We gave particular emphasis to exploring the pre-harvest and post-harvest stages in farms. This paper also proposed some solutions for food waste.

Although this paper has cited published data, the lack of first-hand data limits full discussion of some topics.

\section{Acknowledgements}

This research is partially supported by the Tianjin Municipal Social Science Fund (No. TJGL16-024) and Scientific Research Foundation for the Returned Overseas Chinese Scholars, State Education Ministry.

\section{Reference}

1. Blond, R. D. (1984). The agricultural development systems project in Egypt. Univ. Calif., Davis, 42-48.

2. Broekmeulen, R. A., \& van Donselaar, K. H. (2009). A heuristic to manage perishable inventory with batch ordering, positive lead-times, and time-varying demand. Computers \& Operations Research, 36(11), 3013-3018.

3. Corrado, M. (2007). Understanding Consumer Food Management Behaviour. Wrap, Banbury, UK.

4. Crittenden, B. D., Kolaczkowski, S. T., \& Kolaczkowski, S. (1995). Waste minimization: a practical guide: IChemE.

5. Cruijssen, F., Cools, M., \& Dullaert, W. (2007). Horizontal cooperation in logistics: opportunities and impediments. Transportation Research Part E: Logistics and Transportation Review, 43(2), 129-142.

6. Doganis, P., Alexandridis, A., Patrinos, P., \& Sarimveis, H. (2006). Time series sales forecasting for short shelf-life food products based on artificial neural networks and evolutionary computing. Journal of Food Engineering, 75(2), 196-204.

7. Environmental Protection Agency (2012). Food Reduction

Challenge. http://www.epa.gov/foodrecovery challenge/ (Accessed Spetember 25, 2012)

8. FAO (1981) Food loss prevention in perishable crops. FAO Agricultural Service Bulletin, no. 43, FAO Statistics Division.

9. Food waste costs global economy $\$ 750$ billion. (2013, 2013/11//). Nutraceuticals World, 16, 12.

10. Garnett, T. (2006). Fruit and vegetables \& UK greenhouse gas emissions: exploring the relationship. UK: Food and Climate Research Network, University of Surrey.

11. George Morris Centre Value Chain, Management Centre, Canadian, E.L., \& Cut Waste Grow, P. F. (2012). Cut waste, grow profit how to reduce and manage food waste, leading to increased profitability and environmental sustainability. Guelph, Ont.: Guelph, Ont.: Value Chain Management Centre, George Morris Centre.

12. Gooch, M., Felfel, Abdel, Glasbey, Caroline, George Morris Centre. Value Chain Management Centre, publisher, \& Canadian Electronic Library , distributor. (2015). " the cost of Canada's annual food waste (Canadian Electronic Library. Documents collection).

13. Guerra, M., Vivas, Z., Quintero, I., \& Zambrano de Valera, J. (1998). Estudio de las perdidas postcosecha en nueve rubros horticolas. In Proc. Interam. Soc. Trop. Hort (Vol. 42, pp. 404-411).

14. Gunders, D. (2012). Wasted: How America is losing up to 40 percent of its food from farm to fork to landfill. Natural Resources Defense Council Issue Paper. August. This report was made possible through the generous support of The California 
Endowment.

15. Iacovidou, E., Ohandja, D.-G., \& Voulvoulis, N. (2012). Food waste disposal units in UK households: The need for policy intervention. Science of the Total Environment, 423, 1-7.

16. Jedermann, R., Nicometo, M., Uysal, I., \& Lang, W. (2014). Reducing food losses by intelligent food logistics. Philosophical Transactions of the Royal Society of London A: Mathematical, Physical and Engineering Sciences, 372(2017), 20130302.

17. Kader, A. A. (2004, June). Increasing food availability by reducing postharvest losses of fresh produce. In V International Postharvest Symposium 682 (pp. 21692176).

18. Kantor, L. S., Lipton, K., Manchester, A., \& Oliveira, V. (1997). Estimating and addressing America's food losses. Food Review, 20(1), 2-12.

19. Katajajuuri, J.-M., Silvennoinen, K., Hartikainen, H., Heikkilä, L., \& Reinikainen, A. (2014). Food waste in the Finnish food chain. Journal of Cleaner Production, 73, 322-329.

20. Koivupuro, H. K., Hartikainen, H., Silvennoinen, K., Katajajuuri, J. M., Heikintalo, N., Reinikainen, A., \& Jalkanen, L. (2012). Influence of socio demographical, behavioural and attitudinal factors on the amount of avoidable food waste generated in Finnish households. International Journal of Consumer Studies, 36(2), 183-191.

21. Krajewska, M. A., Kopfer, H., Laporte, G., Ropke, S., \& Zaccour, G. (2008). Horizontal cooperation among freight carriers: request allocation and profit sharing. Journal of the Operational Research Society, 59(11), 1483-1491.

22. Kummu, M., De Moel, H., Porkka, M., Siebert, S., Varis, O., \& Ward, P. (2012). Lost food, wasted resources: Global food supply chain losses and their impacts on freshwater, cropland, and fertiliser use. Science of the Total Environment, 438, 477-489.

23. Lin, J., Zuo, J., Gan, L., Li, P., Liu, F., Wang, K., . . . Gan, H. (2011). Effects of mixture ratio on anaerobic co-digestion with fruit and vegetable waste and food waste of China. Journal of Environmental Sciences, 23(8), 1403-1408.

24. Lummus, R. R., Krumwiede, D. W., \& Vokurka, R. J. (2001). The relationship of logistics to supply chain management: developing a common industry definition. Industrial Management \& Data Systems, 101(8), 426-432.

25. Lundqvist, J., de Fraiture, C., \& Molden, D. (2008). Saving water: from field to fork: curbing losses and wastage in the food chain.

26. Murthy, D. S., Gajanana, T., Sudha, M., \& Dakshinamoorthy, V. (2009). Marketing and postharvest losses in fruits: its implications on availability and economy. Marketing, 64(2).

27. National Academy of Sciences (1978). Post-harvest food losses in developing countries. Washington, DC: National Academy of Sciences.
28. Parfitt, J., Barthel, M., \& Macnaughton, S. (2010). Food waste within food supply chains: quantification and potential for change to 2050. Philosophical Transactions of the Royal Society B: Biological Sciences, 365(1554), 3065-3081.

29. Pinstrup-Andersen, P. (2002). Food and agricultural policy for a globalizing world: Preparing for the future. American Journal of Agricultural Economics, 1201-1214.

30. Quested, T., \& Johnson, H. (2009). Household food and drink waste in the UK: final report: Wastes \& Resources Action Programme (WRAP).

31. Rolle, R. (2006). Improving postharvest management and marketing in the Asia-Pacific region: issues and challenges. Paper presented at the Postharvest management of fruit and vegetables in the Asia-Pacific Region. Reports of the APO Seminars on Reduction of postharvest losses of fruits and vegetables, India, 5-11 October, 2004, and Marketing and food safety: challenges in postharvest management of agricultural/horticultural products, Islamic Republic of Iran, 23-28 July, 2005.

32. Stuart, T. (2009). Waste: uncovering the global food scandal. WW Norton \& Company.

33. Takata, M., Fukushima, K., Kino-Kimata, N., Nagao, N., Niwa, C., \& Toda, T. (2012). The effects of recycling loops in food waste management in Japan: based on the environmental and economic evaluation of food recycling. Science of the Total Environment, 432, 309-317.

34. Tanimura, E. (2008). Amendment to the Food Recycling Law and promotion of "recycle loop". Waste Management Research, 19(4), 166-170.

35. Uzea, N., Gooch, M., and Sparling, D. (2013). Developing an Industry Led Approach to Addressing Food Waste in Canada. Provision Coalition. Retrieved from http://nbs.net/wpcontent/ uploads/Addressing-Food-Waste-in-Canada.pdf

36. Williams, H., \& Wikström, F. (2011). Environmental impact of packaging and food losses in a life cycle perspective: a comparative analysis of five food items. Journal of Cleaner Production, 19(1), 43-48.

37. Williams, H., Wikström, F., \& Löfgren, M. (2008). A life cycle perspective on environmental effects of customer focused packaging development. Journal of Cleaner Production, 16(7), 853-859.

38. Williams, H., Wikström, F., Otterbring, T., Löfgren, M., \& Gustafsson, A. (2012). Reasons for household food waste with special attention to packaging. Journal of Cleaner Production, 24, 141-148.

39. Zhang, R., El-Mashad, H. M., Hartman, K., Wang, F., Liu, G., Choate, C., \& Gamble, P. (2007). Characterization of food waste as feedstock for anaerobic digestion. Bioresource technology, 98(4), 929-935. 